\title{
Aktivitas Antibakteri Ekstrak Dan Fraksi Daun Manggis (Garcinia Mangostana) Terhadap Staphylococcus aureus
}

\section{Antibacterial Activity of Mangosteen (Garcinia Mangostana) Leaf Extracts and Fractions Against Staphylococcus aureus}

\author{
Taufik Turahman ${ }^{1 *}$, Ghani Nurfiana Fadma Sari ${ }^{1}$ \\ Fakultas Farmasi Universitas Setia Budi Surakarta \\ JIn. Letjen Sutoyo-Mojosongo Surakarta-57127 Telp. 0271-852518 \\ email: taufikturahman@gmail.com
}

\begin{abstract}
ABSTRAK
Penyakit infeksi masih merupakan salah satu masalah kesehatan masyarakat yang penting untuk diperhatikan khususnya di negara berkembang. Daun Manggis (Garcinia mangostana L.) merupakan tanaman yang cukup dikenal yang bermanfaat sebagai antioksidan, antibakteri, dan antikanker. Penelitian ini bertujuan untuk mengetahui kandungan kimia dan aktivitas antibakteri dari ekstrak etanol, fraksi n-heksan, etil asetat dan air daun manggis (Garcinia mangostana L.) terhadap Staphylococcus aureus secara difusi dan dilusi

Daun manggis diekstraksi dengan cara maserasi menggunakan etanol 96\% kemudian dilanjutkan fraksinasi menggunakan metode ekstraksi cair-cair. Selanjutnya diuji aktivitas antibakterinya dengan metode difusi cakram dengan konsentrasi $12.5 \%, 25 \%$ dan $50 \%$. Kontrol positif yang digunakan adalah ciprofloksasin $5 \mu \mathrm{g} /$ disk dan kontrol negatif Tween $805 \%$. Uji dilusi dilakukan terhadap ekstrak yang paling aktif dengan melihat KHM dan KBM nya. Identifikasi golongan senyawa dapat dilakukan dengan menggunakan metode Kromatografi Lapis Tipis.

Hasil pengujian aktifitas antibakteri menunjukan diameter zona hambat terbesar pada bakteri Staphylococcus aureus terdapat pada fraksi air daun manggis konsentrasi $50 \%$ dengan diameter zona hambat $(10 \mathrm{~mm})$. Hasil kadar hambat minimum KHM dan kadar bunuh minimum KBM pada konsentrasi $12.5 \%$. Hasil uji KLT menunjukkan bahwa dalam ekstrak dan fraksi daun manggis mengandung senyawa flavonoid, saponin dan steroid.
\end{abstract}

Kata kunci : Antibakteri, Daun Manggis (Garcinia mangostana), Staphylococcus aureus

\section{ABSTRACT}

Infectious diseases are still one of the important public health problems to be considered especially in developing countries. Mangosteen leaf (Garcinia mangostana L.) is a well-known plant that is useful as an antioxidant, antibacterial and anticancer. This study aims to determine the chemical content and antibacterial activity of ethanol extract, $n$-hexane fraction, ethyl acetate and water of mangosteen leaves (Garcinia mangostana L.) on Staphylococcus aureus by diffusion and dilution

Mangosteen leaves were extracted by maceration using $96 \%$ ethanol then continued by fractionation using a liquid-liquid extraction method. Antibacterial activity was then tested using disc diffusion method with a concentration of $12.5 \%, 25 \%$ and $50 \%$. Positive control used was ciprofloxacin $5 \mu \mathrm{g} /$ disk and negative control of $5 \%$ Tween 80 . Dilution test was carried out on the most active extract by looking at the MIC and MBC. Identification of compound groups can be done using Thin Layer Chromatography method.

The results of antibacterial activity testing showed that the diameter of the largest inhibitory zone in Staphylococcus aureus bacteria was found in the water fraction of mangosteen leaves at $50 \%$ concentration with inhibition zone diameter $(10 \mathrm{~mm})$. The results of the minimum MIC inhibitory level and the minimum suicide rate of MBC at a concentration of $12.5 \%$. The TLC test results showed that in the extracts and fractions of mangosteen leaves contained flavonoids, saponins and steroids

Key word : Antibacterial, Mangosteen Leaf (Garcinia mangostana), Staphylococcus aureus 


\section{PENDAHULUAN}

Penyakit infeksi merupakan salah satu masalah kesehatan yang semakin meningkat. Infeksi dapat disebabkan oleh virus, jamur, parasite dan bakteri. Staphylococcus aureus adalah bakteri yang berbentuk bulat, sering berkelompok yang tidak beraturan dan merupakan bakteri gram positf (Volk, dkk, 1990). Staphylococcus aureus sering menimbulkan penyakit pada manusia. Infeksi oleh bakteri ini menyebabkan timbulnya penyakit dengan tanda-tanda khas yaitu peradangan, nekrosis, dan pembentukan abses.

Pengobatan penyakit infeksi bisa menggunaan antibiotik, akan tetapi penggunaan antibiotik yang tidak sesuai aturan menjadi penyebab utama terjadinya resistensi. Oleh karena itu dengan berkembangnya resistensi tersebut harus diimbangi dengan penemuan sumber antibakteri baru yang dapat membunuh bakteri maupun menghambat pertembuhannya. Penemuan sumber antibakteri tersebut dapat berasal dari alam maupun sintetik (Kamila, 2014)

Manggis merupakan tanaman yang seluruh bagian tanamannya dapat dimanfaatkan, mulai dari daging buah, kulit buah, daun, batang dan akar. Manggis mempunyai kandungan senyawa turunan xanton yang mempunyai aktivitas biologi sebagai antibakteri, antimikroba, anti inflamasi, antioksidan, dan dapat menghambat pertumbuhan sel kanker usus (Putra, 2010).

Menurut (Poeloengan dkk, 2010) Ekstrak kulit buah manggis memiliki aktivitas antibakteri sebesar $10 \mathrm{~mm}$ terhadap Stapylococcus aureus pada konsentrasi $25 \%$ dan mempunyai nilai KBM sebesar $2 \%$. Penelitian lain juga menunjukkan bahwa fraksi etil asetat dari ekstrak kulit buah manggis pada konsentrasi $5 \%$ mempunyai aktifitas antibakteri sebesar $17 \mathrm{~mm}$ terhadap Escherichia coli dan mempunyai nilai KHM sebesar $5 \%$.

Berdasarkan uraian diatas, peneliti tertarik untuk meneliti golongan senyawa kimia dari daun manggis yang aktif sebagai antibakteri, sehingga perlu dilakukan pemisahan untuk memperoleh fraksi aktif dengan kandungan senyawa lebih sederhana.

Fraksi aktif diperoleh dari hasil fraksinasi menggunakan pelarut $n$ heksan, etil-asetat dan air. Masingmasing fraksi dan ekstrak nantinya akan diuji antibakteri secara difusi dan dilusi terhadap bakteri Staphylococcus aureus ATCC 25923

\section{METODE PENELITIAN}

\section{Alat}

Peralatan yang digunakan adalah bejana maserasi, corong pisah, cawan porselen, moisture balance, corong pisah, evaporator, ayakan nomor 40, peralatan gelas ( Pyrex), neraca analitik, lampu UV, kertas saring, lempeng KLT, tabung reaksi, cawan petri, jarum ose, kapas lidi steril, kotak aseptis inkas, gelas ukur, batang pengaduk, kertas cakram.

\section{Bahan}

Bahan utama yang digunakan adalah daun manggis yang ditanam di daerah Wonogiri, Jawa Tengah. Bahan kimia yang digunakan meliputi $n$ heksana, etil-asetat, etanol $96 \%$, aquadest, pereaksi dragendorff, 
pereaksi Lieberman Burchard, pereaksi anisaldehid, pereaksi sitro borat, Media Nutrient Agar (NA), Brain Heart Infuction (BHI), dan muller Hinton Agar (MHA), bakteri Staphylococcus aureus ATCC 25923.

\section{Pembuatan Ekstrak Etanolik Daun manggis}

Ekstrak etanolik dibuat dengan cara, $1000 \mathrm{~g}$ serbuk daun manggis dimasukkan dalam botol gelap kemudian ditambah dengan etanol $96 \%$ sebanyak $7500 \mathrm{ml}$. Maserasi dilakukan selama lima hari dengan penggojogan. Setelah itu dipisahkan antara filtrat dengan ampas. Ekstrak yang diperoleh dipekatkan dengan vacuum rotaevaporator suhu $40^{\circ} \mathrm{C}$ ), selanjutnya disebut ekstrak etanolik daun manggis

Pembuatan Fraksi $n$-Heksana, Fraksi Etil Asetat, dan Fraksi Air

Ekstrak etanolik sebanyak $10 \mathrm{~g}$ kemudian disuspensi dengan air sebanyak $75 \mathrm{ml}$ lalu dipartisi dengan $n$ heksana $75 \mathrm{ml}$ dan di replikasi sebanyak tiga kali menggunakan corong pisah. Lapisan $n$-heksana selanjutnya dikumpulkan dan dipekatkan dengan vaccum rotaevaporator, filtrat $n$-heksana yang kering ini selanjutnya disebut fraksi $n$-heksana. Lapisan air sisa partisi dengan $n$-heksan kemudian dipartisi lagi dengan $75 \mathrm{ml}$ etil asetat dan di replikasi sebanyak tiga kali. Lapisan etil asetat dipisahkan dan dipekatkan dengan vaccum rotaevaporator dan diperoleh fraksi etil asetat. Lapisan air diuapkan di atas waterbath sampai kental, yang kemudian disebut fraksi air. Fraksi yang didapat masing-masing ditimbang untuk mendapat persen rendemen terhadap bobot awal.

\section{Identifikasi Kandungan Flavonoid secara Kromatografi Lapis Tipis (KLT)}

Identifikasi golongan senyawa dapat dilakukan dengan menggunakan KLT. Identifikasi golongan senyawa dilakukan terhadap ekstrak dan fraksi yang diperoleh dengan melihat hasil dari penampak bercak yang bereaksi dengan reagen di antaranya: flavonoid (uap Ammonia dan pereaksi Sitroborat), alkaloid (pereaksi Dragendroff), steroid (pereaksi Liberman bourchard), tanin (Pereaksi $\mathrm{FeCl}_{3}$ ), saponin (Pereaksi Anisaldehid).

Uji kualitatif ini dilakukan untuk membuktikan kebenaran bahan/zat aktif yang terkandung pada daun manggis yang berperan dalam aktivitas antibakteri.

\section{Pengujian Aktivitas Antibakteri secara difusi cakram}

Media MHA (Muller Hinton Agar) yang sudah disterilkan dituang secara aseptis sebanyak $50 \mathrm{ml}$ pada cawan petri $15 \mathrm{~cm}$ yang sudah disterilkan hingga merata, kemudian dibiarkan hingga membeku. Setelah media MHA membeku, celupkan 1 ose kapas kedalam suspensi bakteri, kemudian inokulasikan bakteri yang telah diambil dengan ose tersebut pada media MHA. Paper disc kosong Steril (diameter 6 $\mathrm{mm}$ ) direndam dalam ekstrak, fraksi $n-$ heksana, etil asetat dan air yang masing-masing dilarutkan dalam Tween $805 \%$, kemudian paper disc yang telah direndam larutan ekstrak, ditunggu selama 5 menit sampai ekstrak tersebut menyerap pada paper disc dan diletakkan diatas permukaan lempeng agar yang telah diinokulasikan bakteri. Kontrol negatif digunakan Tween 80 
$5 \%$, Kontrol positif digunakan antibiotik Ciprofloxacin 5ug. Selanjutnya diinkubasi pada temperatur $37^{\circ} \mathrm{C}$ selama 24 jam.

Zona hambat yang terbentuk diukur dengan menggunakan jangka sorong. Pengujian dilakukan sebanyak dua kali (duplo)

Tahap uji antibakteri yang kedua adalah metode dilusi menggunakan beberapa pengenceran yang bertujuan untuk menentukan kadar hambat minimum KHM dan kadar bunuh minimum (KBM) terhadap bakteri Staphylococcus aureus.

\section{HASIL DAN PEMBAHASAN}

\section{Hasil Ekstraksi dan Fraksinasi}

Ekstrak kental etanolik yang didapatkan dari $1000 \mathrm{~g}$ serbuk adalah 296,430 g sehingga memiliki rendemen sebesar 29,640\%. Ekstraksi dilakukan dengan etanol karena etanol merupakan pelarut universal sehingga dapat mengekstraksi hampir semua kandungan kimia dalam simplisia. Ekstrak kental etanolik sebanyak $10 \mathrm{~g}$ kemudian dilakukan fraksinasi dengan $n$-heksana, etil asetat, dan air dimaksudkan untuk memisahkan senyawa berdasarkan polaritasnya, dimana fase $n$-heksana akan melarutkan kandungan senyawa tanaman yang bersifat nonpolar, fase etil asetat melarutkan senyawa yang bersifat semipolar, dan fase air melarutkan kandungan senyawa kimia tanaman yang bersifat polar. Hasil partisi dapat dilihat pada Tabel 1 setelah dilakukan 3 kali replikasi.

\section{Hasil identifikasi kandungan senyawa kimia ekstrak etanol daun} manggis menggunakan metode KLT Ekstrak etanol herba manggis yang diperoleh melalui metode maserasi, kemudian dianalisis kandungan kimianya menggunakan metode kromatografi lapis tipis (KLT). Senyawa yang akan diidentifikasi yaitu alkaloid, flavonoid, steroid, tannin dan saponin. Fase diam yang digunakan yaitu Silika Gel GF 254 dan menggunakan fase gerak yang berbeda-beda berdasakan polaritas senyawa, Hasil identifikasi kandungan senyawa tersebut dapat dilihat pada tabel 2.

\section{Tabel 1. Hasil fraksinasi ekstrak etanolik daun manggis}

\begin{tabular}{lcc}
\hline Nama pelarut & Berat $(\mathrm{g})$ & Rendemen (\%) \\
\hline n-heksan & 8,997 & 26,67 \\
\hline etil asetat & 19,287 & 32,14 \\
Air & 23,425 & 39,04 \\
\hline
\end{tabular}


Tabel 2. Hasil identifikasi senyawa setiap fraksi dari ekstrak daun manggis

\begin{tabular}{cccccc}
\hline Uji & Alkaloid & Flavonoid & Steroid & Saponin & Tanin \\
\hline Ekstrak & - & + & + & + & - \\
$n$-heksana & - & + & + & + & - \\
Etil asetat & - & + & + & + & - \\
Air & - & + & - & + & - \\
\hline
\end{tabular}

Dari hasil identifikasi kandungan senyawa ini dapat disimpulkan bahwa daun manggis mengandung senyawa flavonoid, steroid dan saponin baik pada ekstrak maupun pada masing-masing fraksinya.

\section{Hasil uji aktivitas antibakteri}

Tahap uji antibakteri yang pertama adalah proses screening dengan metode difusi cakram yang bertujuan untuk menentukan ekstrak dan fraksi yang mempunyai aktivitas antibakteri tertinggi. Aktivitas antibakteri ditentukan melalui besarnya diameter zona hambat yang terbentuk disekitar kertas cakram dengan menggunakan tiga kelompok perlakuan pada setiap ekstrak dan fraksi dengan masing-masing konsentrasi
$12,5 \%, 25 \%$ dan $50 \%$ serta dua kelompok kontrol positif menggunakan ciprofloxacin 5 $\mathrm{g} / \mathrm{disk}$ dan kontrol negatif menggunakan tween 80 5\% steril. Penggunaan ciprofloxacin sebagai kontrol positif didasarkan pada sifatnya yang memiliki spektrum luas, dan sensitif terhadap Staphylococcus aureus. Hasil uji aktivitas antibakteri tersebut dapat dilihat pada tabel 3.

Pada uji difusi lempeng agar zona hambat yang terbentuk berukuran kurang dari $\leq 5 \mathrm{~mm}$, maka respon zona hambat dikategorikan lemah. Jika zona hambat yang terbentuk 6-10 mm, maka respon zona hambat masuk kedalam kategori sedang, sedangkan 11-20 mm kuat, dan $\geq 20 \mathrm{~mm}$ sangat kuat

Tabel 3. Rata - rata diameter zona hambat yang dihasilkan ekstrak, fraksi $n$ heksana, etil asetat dan air pada bakteri Staphylococcus aureus

\begin{tabular}{|c|c|c|c|c|c|c|c|}
\hline \multirow[b]{2}{*}{ Bakteri } & \multicolumn{7}{|c|}{ Rata-Rata Diameter Zona Hambat (mm) } \\
\hline & Konsentrasi & Ekstrak & F n-heksana & F-etil asetat & Fraksi air & $\mathrm{K}+$ & K- \\
\hline \multirow{3}{*}{$S$ aureus } & $12,5 \%$ & - & 3 & - & 7.5 & \multirow{3}{*}{25} & \multirow{3}{*}{ - } \\
\hline & $25 \%$ & 7.5 & 5 & 8.6 & 8 & & \\
\hline & $50 \%$ & 8 & 5.5 & 9 & 10 & & \\
\hline
\end{tabular}

Keterangan:

- Pengukuran diameter zona hambat termasuk diameter kertas cakram (6 mm)

- Tanda (-) menunjukkan tidak terbentuknya zona hambat 
Hasil uji aktivitas antibakteri ekstrak dan fraksi daun Manggis (Garcinia mangostana) terhadap Staphylococcus dengan variasi konsentrasi $12,5 \%, 25 \%$ dan $50 \%$ dengan tiga kali pengulangan setelah diinkubasi selama 24 jam pada suhu $37^{\circ} \mathrm{C}$ memiliki respon penghambatan yang lemah sampai sedang $(<11 \mathrm{~mm})$ sedangkan kontrol positif ciprofloxacin $5 \mu \mathrm{g}$ menunjukkan adanya aktivitas antibakteri yang ditandai dengan adanya zona hambat yang terbentuk di sekitar kertas cakram dengan diameter zona hambat rata-rata $25 \mathrm{~mm}$ pada Staphylococcus aureus

kontrol negatif pada penelitian ini menggunakan tween 80 (5\%) steril menunjukkan tidak adanya aktivitas antibakteri yang ditandai dengan tidak terbentuknya zona hambat di sekitar kertas cakram. Pemilihan tween 80 steril sebagai kontrol negatif dikarenakan pada saat pembuatan seri konsentrasi ekstrak dan fraksi tidak semua dapat melarut atau tercampur pada pelarut polar sehingga dengan penambahan

tween 80 sebagai surfaktan dalam larutan akan menyebabkan turunnya tegangan permukaan larutan sehingga meningkatkan proses kelarutan pada saat pembuatan seri konsentrasi.

Hasil pengujian secara difusi menunjukan diameter zona hambat terbesar pada bakteri Staphylococcus aureus terdapat pada fraksi air daun manggis konsentrasi $50 \%$ dengan diameter zona hambat $(10 \mathrm{~mm})$, Hasil uji aktivitas antibakteri ekstrak dan fraksi daun Manggis (Garcinia mangostana) terhadap Staphylococcus aureus dapat dilihat pada gambar 1.

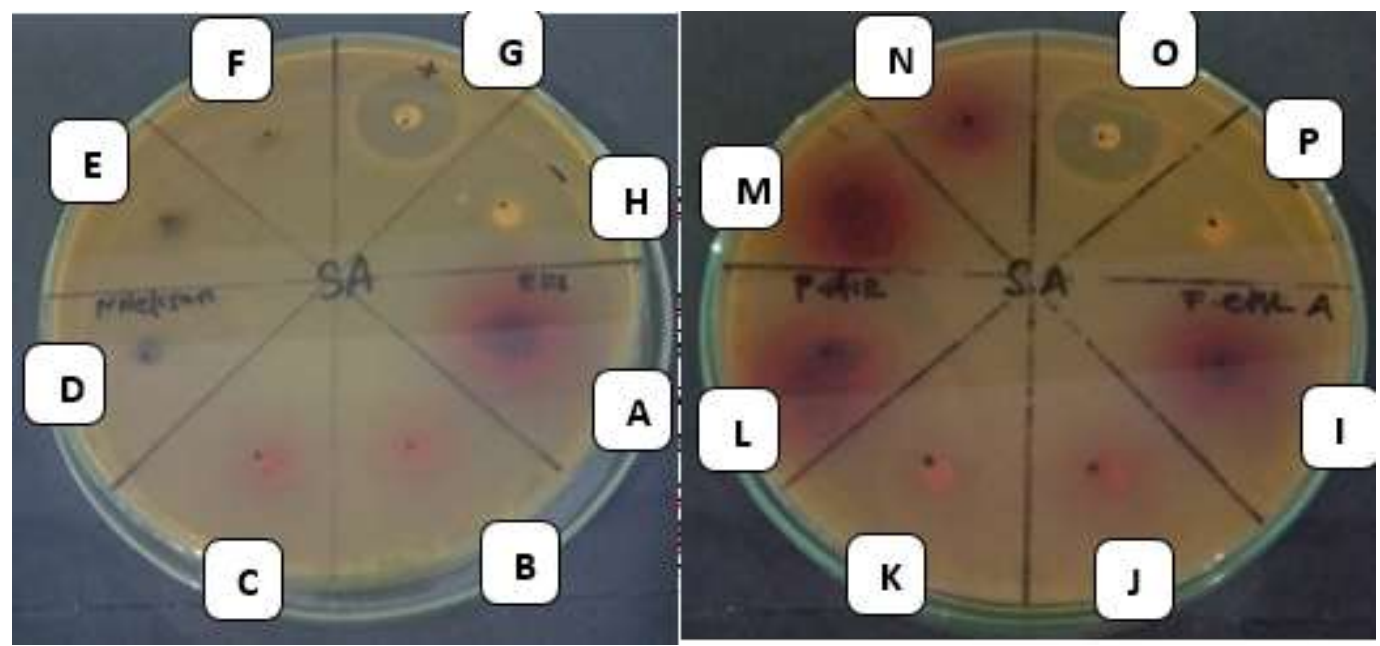

Gambar 1. Hasil Uji Aktivitas Antibakteri Ekstrak Daun Manggis Pada Staphylococcus Aureus Konsentrasi 50\% (A), Ekstrak 25\% (B), Ekstrak 12,5\% (C), Fraksi N-Heksan Konsentrasi 50\% (D), N-Heksan 25\% (E), N-Heksan 12,5\% (F), Kontrol Positif Ciprofloxacin (G \& O), Kontrol Negatif Tween 80 (H \& P), Fraksi Etil Asetat Konsentrasi 50\% (I), Etil Asetat 25\% (J), Etil Asetat 12,5\% (K), Fraksi Air Konsentrasi $50 \%$ (L), Air 25\% (M), Air 12,5\% (N) 
Tabel 4. Kadar hambat minimum fraksi air daun manggis pada bakteri Staphylococcus aureus

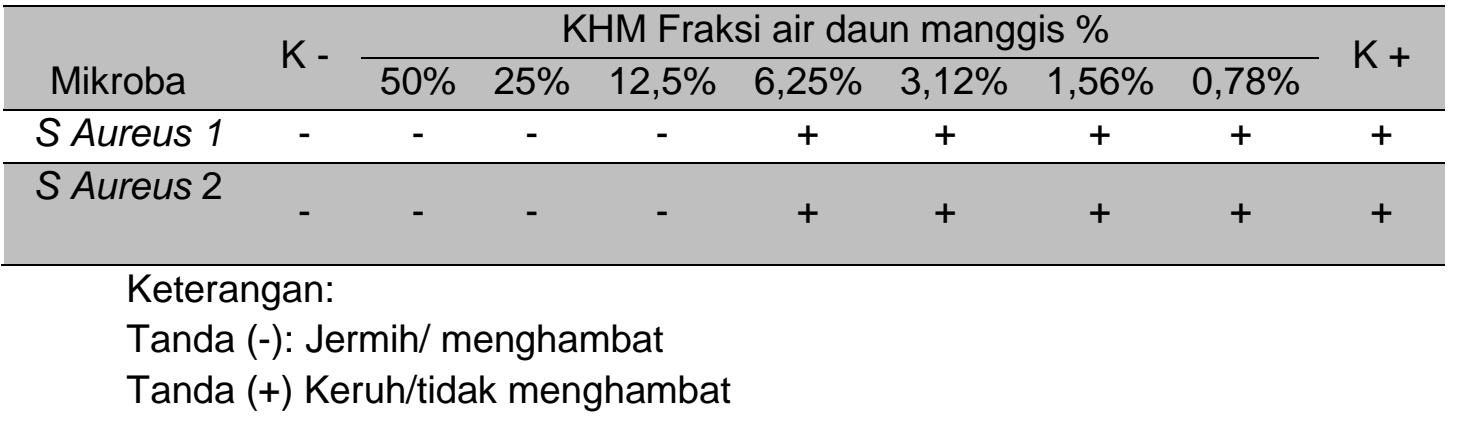

Tabel 5. Kadar bunuh minimum fraksi air Daun manggis pada bakteri Staphylococcus aureus

\begin{tabular}{|c|c|c|c|c|c|c|c|c|c|}
\hline \multirow[b]{2}{*}{ Mikroba } & \multirow{2}{*}{ K - } & \multicolumn{7}{|c|}{ KBM Fraksi air daun manggis $\%$} & \multirow{2}{*}{$\mathrm{K}+$} \\
\hline & & $50 \%$ & $25 \%$ & $12,5 \%$ & $6,25 \%$ & $3,12 \%$ & $1,56 \%$ & $0,78 \%$ & \\
\hline S Aureus 1 & - & - & - & - & + & + & + & + & + \\
\hline S Aureus 2 & - & - & - & - & + & + & + & + & + \\
\hline
\end{tabular}

Keterangan:

Tanda (-): Jermih/ menghambat

Tanda (+) Keruh/tidak menghambat

Dari hasil penelitian diatas dapat dilihat bahwa fraksi air daun manggis memiliki kadar hambat minimum pada bakteri Staphylococcus aureus yang dilakukan dengan 2 kali replikasi menunjukan kadar hambat minimum masing-masing pada konsenrasi $12,5 \%$ terbukti dengan tidak terbentuknya warna keruh (tidak adanya endapan) pada tabung reaksi.

Pada pengujian KBM dilakukan dengan menanam kembali sediaan uji yang telah diketahui KHM-nya kedalam Nutrient agar tanpa senyawa uji selama 24 jam kemudian diamati ada atau tidaknya pertumbuhan bakteri. Dari hasil penelitian dapat dilihat bahwa konsentrasi bunuh minimum fraksi air daun manggis terhadap bakteri Staphylococcus aureus yang dilakukan dengan 2 kali replikasi menunjukan kadar bunuh minimum (KBM) pada konsenrasi $12,5 \%$ terbukti dengan tidak tumbuhnya bakteri dari hasil KHM yang di inokulasikan pada media Nutrient agar setelah diinkubasi selama 24 jam pada suhu $37^{\circ} \mathrm{C}$.

\section{KESIMPULAN}

Ekstrak dan fraksi daun manggis memiliki aktivitas antibakteri terhadap Staphylococcus aureus dengan diameter zona hambat $<10 \mathrm{~mm}$ sedangkan diameter zona hambat kontrol positif Ciprofloxacin $25 \mathrm{~mm}$. hasil uji kadar hambat minimun $\mathrm{KHM}$ dan kadar bunuh minimum KBM pada konsentrasi $12.5 \%$. Ekstrak dan fraksi daun manggis memiliki kandungan senyawa flavonoid, steroid dan saponin. 


\section{UCAPAN TERIMA KASIH}

Tim Peneliti menyampaikan banyak terima kasih kepada LPPM Universitas Setia Budi Surakarta yang telah mendanai penelitian ini sehingga penelitian ini bisa berjalan dengan baik dan bermanfaat bagi perkembangan ilmu pengetahuan.

\section{DAFTAR PUSTAKA}

Gopalakrishnan G, N. Banumathi B, Suresh G. 1997. Evaluation of the antifungal activity of natural xanthones from Garcinia mangostana and their synthetic derivates. J. Nat Prod. 50 (5): 519524.

Jawetz, E., Melnick, J.L., Adelberg. E.A. 1986. Mikrobiologi Untuk Profesi Kesehatan. Edisi XVI. Penerjemah: Bonang, G. Jakarta: Penerbit Buku Kedokteran hlm 239-244.

Muhammad Zakiya Kamila. 2014. Uji Aktivitas Antibakteri Ekstrak Dan Fraksi Daun Sintok (Cinnamomum Sintoc Blume.) Terhadap Staphylococcus Aureus Dan Pseudomonas Aeruginosa Serta Analisa Komponen Senyawa Fraksi Aktif Dengan Kromatografi Gas - Spektrometri Massa. [Skripsi]. Uin Syarif Hidyatullah Jakarta

Palakawong, C., Sophanodora, P., Pisuchpen, S., dan Phongpaichit. 2010. Antioxidant and Antimicrobial Activities of Crude Extracts from Mangosteen (Garcinia mangostana L.) Parts and Some Essential Oils. International Food Research
Journal. 17: 583-9

Poeloengan, M., Praptiwi, Praptiwi. Uji Aktivitas Ekstrak Kulit Buah Manggis (Garcinia Mangostana Linn). Media Litbang Kesehatan,2010, Vol. 20 (2): 6569

Putra I Nengah. 2010. Aktivitas Antibakteri Ekstrak Kulit Buah Manggis (Garcinia Mangostana L.) Serta Kandungan Senyawa Aktifnya. J.Teknol. dan Industri Pangan, Vol. XXI No. 1 Th. 2010

Saputro Eko. 2014. Uji Aktivitas Antibakteri Fraksi Etil Asetat. [Skripsi]. UIN. Jakarta

Volk and Wheller. (1984). Mikrobiologi Dasar, diterjemahkan oleh Soenarto Adisoemarto, hal. 137 138, Erlangga, Jakarta.

Yunitasari, L. S. P., 2011, Gempur 41 Penyakit Dengan Buah Manggis: Khasiat dan Cara Pengolahannya untuk Kesehatan, 1st ed., Yogyakarta, Penerbit Pustaka Baru Press, p. 11-2. 